\title{
THE WORLD DATA CENTER SYSTEM
}

by

James F. Lander

Data are the lifeblood of science and the sharing of observations and measurements has always been essential to the formulation of new concepts and the evaluation of existing ones. Since 1957, the World Data Centers have served the international community in a variety of disciplines and in a number of programs, including the Upper Mantle Project and the International Geodynamics Project. In earth sciences, where time and space dependent data are the rule, many years of monitoring observations may be needed and many locales surveyed to distinguish between transient and permanent or normal phenomena.

The practice of operating observatories for the sole purpose of monitoring changes over time is well established in magnetism, seismology, earth and marine tides and other disciplines. The results are frequently shared among observatories, some of which have taken on clearinghouse and service roles. In recent decades, the need for global data has spawned a series of international programs which include concerted observations relating especially to geophysics.

At the beginning of the first of these - the International Geophysical Year (IGY) - it was recognized that a more formal mechanism would be needed to provide for the archiving and dissemination of the relatively large quantities of data that would accumulate. To meet this need, the IGY founders established a system of World Data Centers (WDC's). Both the U.S.A. and the U.S.S.R. agreed to operate WDC's in all disciplines, and these became World Data Centers A and B respectively. Other countries agreed to operate WDC-C's in selected disciplines.

In the U.S.A., there are now WDC's for Solar-Terrestrial Physics, Rockets and Satellites, Meteorology, Rotation of the Earth, Oceanography, Glaciology and Solid Earth Geophysics. These WDC-A's (see box at end) are coordinated by a World Data Center A Coordination Office in the U.S. National Academy of Sciences. In the case of WDC-B's, the work is divided into two centers, B1 and B2, with the same Moscow mailing address, while overall coordination is provided by the Soviet Geophysical Committee. There are several discipline centers in Europe (for example, in Geomagnetism, Ionosphere, Recent Crustal Movements). The ones in Japan cover most of the subdisciplines for Solar-Terrestrial Physics. The multiple WDC's provide security for the data and convenience for the users.

The World Data Centers are founded on a general framework of reciprocity, most of the data being exchanged without cost on a barter system. Non-contributors may acquire the data on a cost-of-copying basis. By agreement, the data centers are open to visitors on notice; in fact, some guest workers spend days or months at a time at WDC-A on a variety of programs.

The Centers operate under the general guidance of the International Council of Scientific Unions (ICSU) Panel on World Data Centres.' Their 'standing orders' are contained in the "Guide to International Data Exchange through World Data Centres", consisting of general principles as well as individual sections of specifics for the different disciplines. The sections are written by scientists and approved by the relevant committees and commissions of the IUGG and its associations, and other international scientific bodies (see Fig. 1).
Figure 1. Schematic of Relationships
for the

World Data Centres for Solid Earth Geophysics

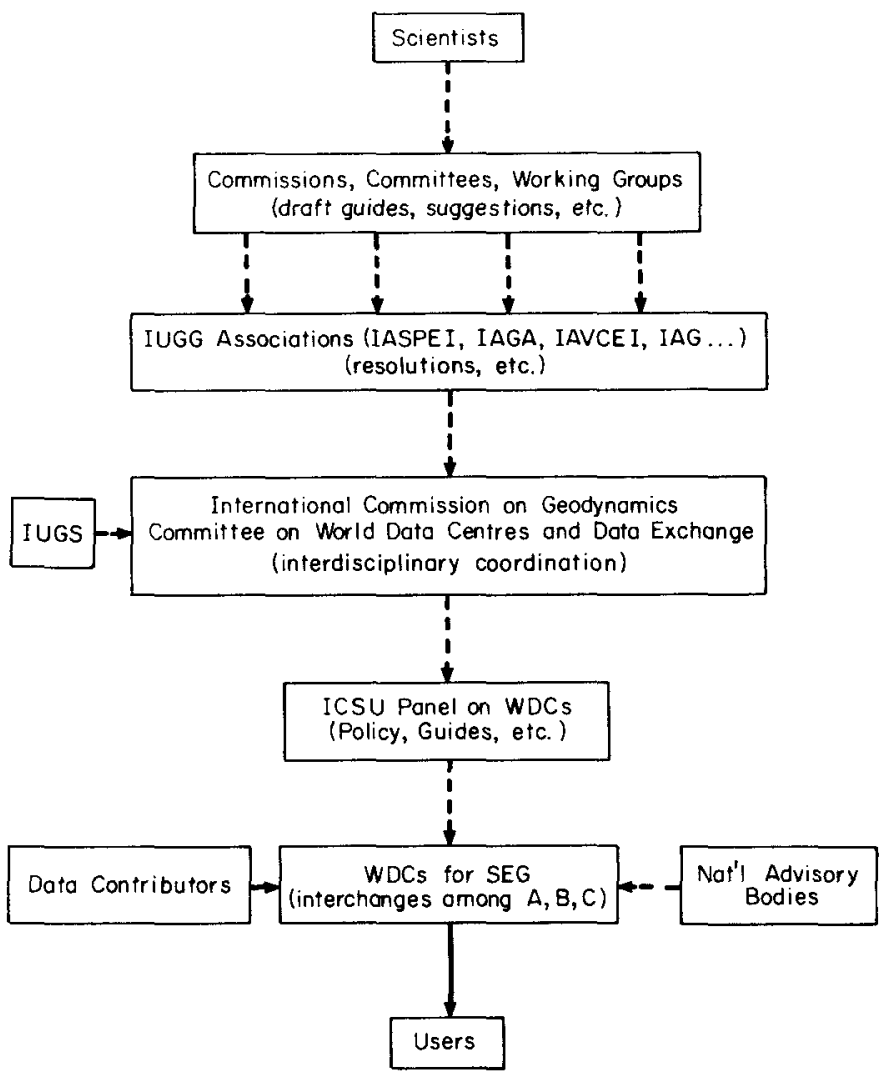

Data, Products, Reports, Referrals

The contents of the Guide are far from static both in terms of their provisions and the subjects to be covered. In fact, there have been so many changes and additions in recent years that the present Guide, now five years old, is being revised and reprinted. Among the additions is a first Guide for the Exchange of Physical and Chemical Volcanological Data.

In addition to the exchanges specified by the Guide, the WDC's are responsive to resolutions adopted by recognized international groups and also assist individual scientists who request data not in their files. WDC-A for Solid Earth 
Geophysics, for example, publishes an irregular series of reports (the "SE" series) which frequently serves as an avenue for an international working group or international program to publish its results. Examples include the report series "Geodynamics International" for the IUGG/IUGS/ICSU International Geodynamics Project; it also published a World Heat Flow map of data compiled by the IASPEI Heat Flow Commission.

The World Data Centers are funded from national sources and, as such, do not deplete the generally small amounts of 'international money' available for scientific activities. In the case of WDC-A for Solid Earth Geophysics, it co-exists with the national data center and serves to make the extensive data and facilities in the national data center more accessible to the international community.

Modern data centers require a wide range of capabilities including duplicating, microfilming, digitizing, computer graphics, plotting and publishing. They must be able to meet the needs of users for analog or digital data and for summaries, searches, maps and other data products. For this reason and to take advantage of the possibilities in producing multidisciplinary data products, it makes sense to operate a number of the smaller activities under one management. Thus, WDC-A for Solid Earth Geophysics includes the disciplines of Seismology, Tsunamis, Gravimetry, Earth Tides, Recent Movement of the Earth's Crust, Magnetic Measurements, Paleomagnetism and Archeomagnetism, and Volcano$\log y$.

A question that is often asked is 'are the data centers really used?' There is now considerable evidence that they are. In Solid Earth Geophysics, for example, the combined national center and WDC-A services about 4,000 requests annually, in addition to publishing some 2,000 pages of data and information about data which is obviously of broad interest. In 1975, the U.S. National Academy of Sciences surveyed the user community and documented a major use in scientific papers of the data obtained through the World Data Center system. The centers also make referrals for data they know are held in institutional or other archives. For the International Geodynamics Project, WDC-A published a Directory of relevant data repositories in the U.S.A. which served to enhance availability of the many types of data on the solid earth.

Many of the data exchanges and data bases maintained by WDC-A and through them by the national data centers are of broad interest to earth scientists. The seismic and volcanological history of a region, seismic reflection profiles on continental margins, rock geochemistry, fossil counts from marine cores, gravity and marine geology are some data sets

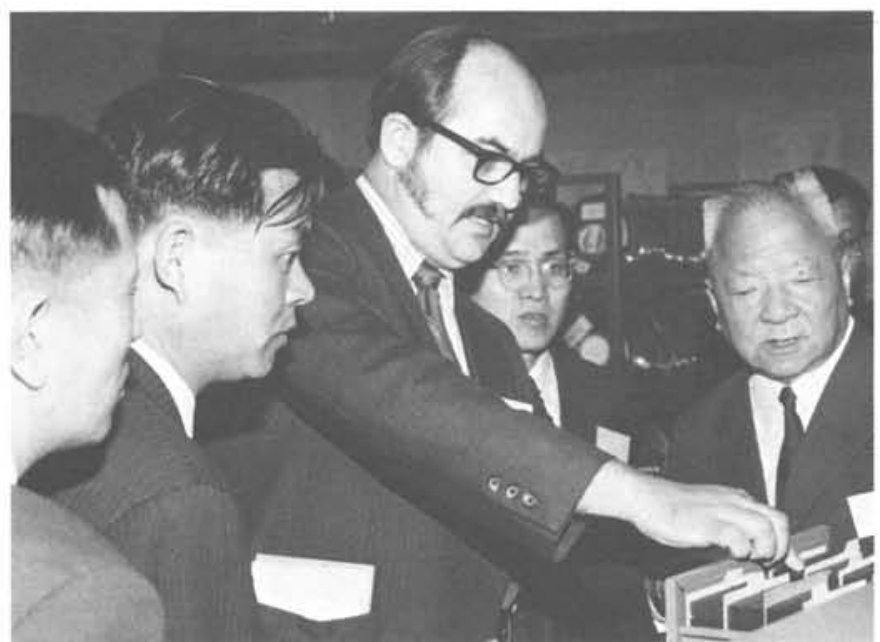

A visiting delegation of scientists from the People's Republic of China inspect the filing of microfilm copies of seismograms during a 1974 visit. (Prof. Ku Kung-hsu on the right is the delegation head; James Lander is in the centre.) Scientists from all over the world visit the data center for periods of a day to a year or more.

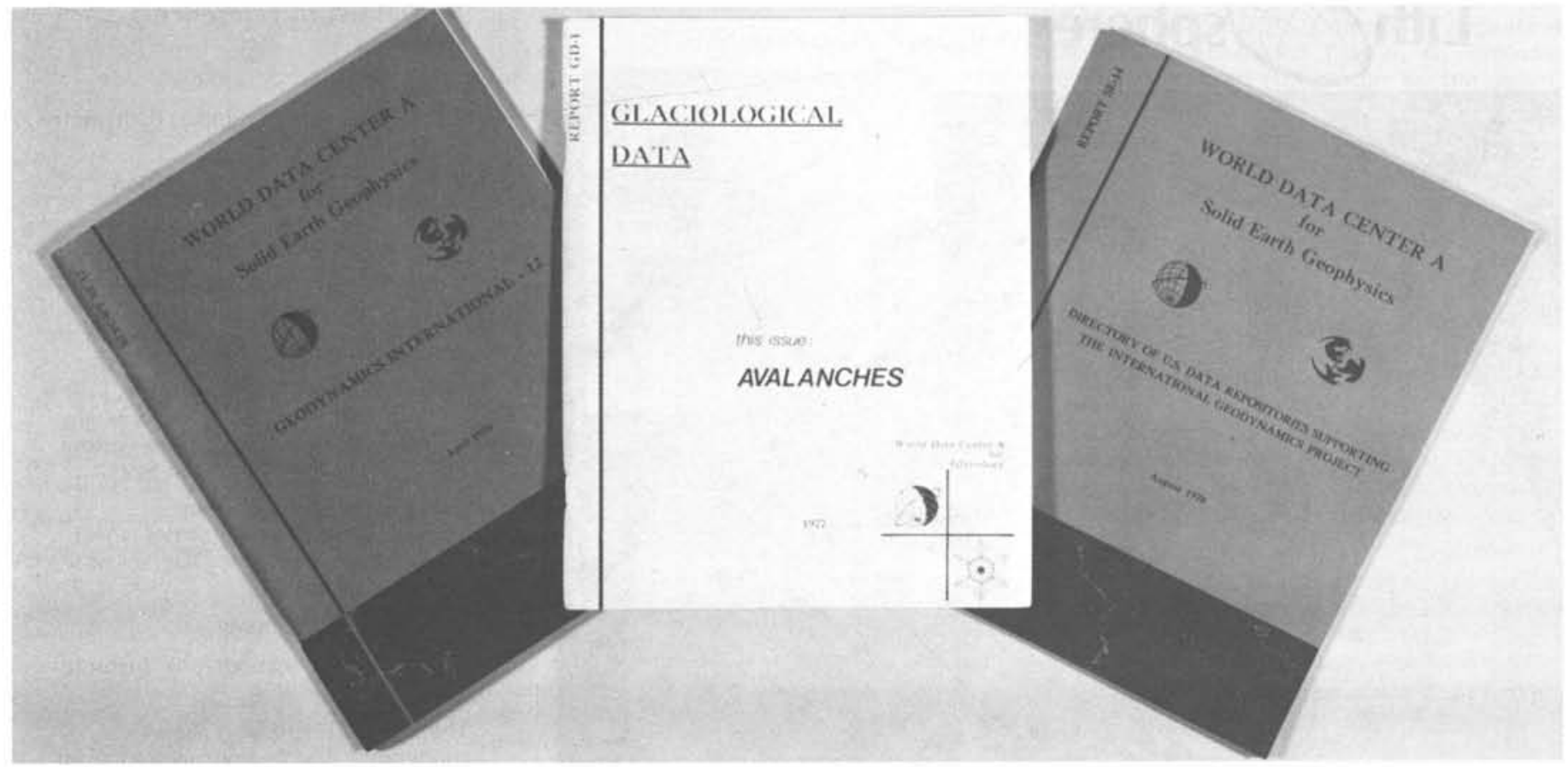

Examples of publications from the WDC-A for Solid-Earth Geophysics SE Report Series and the WDC-A-Glaciology (Snow and Ice) GD Report Series. 
included in the data center holdings. Future guides may include geochronology, geoisotopes, and igneous rock analyses. Frequently, data collected at considerable expense for one purpose may be useful for other or future studies.

As mentioned above, the World Data Center system originally served the scientific activities and disciplines of the International Geophysical Year. Since then some other disciplines have joined, such as tsunamis, volcanology and various specialties in solid earth geophysics. Geology has so far been included mainly through the marine geology aspects of oceanography and petrography in Volcanology. The IUGS is at present connected to the ICSU Panel on WDC's through the International Geodynamics Project representative. The WDC approach to international data exchange and user services has, however, universal application and may be of further interest to the geological community in the near future.

\section{World Data Center A \\ Coordination office \\ National Academy of Sciences \\ 2101 Constitution Avenue, N.W. \\ Washington, D.C., U.S.A., 20418
Telephone: (202) 389-6478}

Glaciology:

World Data Center A: Glaciology (Snow and lce)

Inst. of Arctic \& Alpine Research University of Colorado

Boulder, Colorado, U.S.A. 80309

Telephone: (303) 492-5171

Meteorology (and Nuclear Radiation):

World Data Center A: Meteorology

National Climatic Center

Federal Building

Asheville, North Carolina, U.S.A. 2880

Telephone: (704) 258-2850

Oceanography:

World Data Center A: Oceanography

National Oceanic and Atmospheric

Administration

Washington, D.C., U.S.A. 20235

Telephone: (202) 634-7249

Rockets and Satellites:

World Data Center A: Rockets and Satellites

Goddard Space Flight Center, Code 601

Greenbelt, Maryland, U.S.A. 2077I

Telephone: (301) 982-6695

Rotation of the Earth:

World Data Center A: Rotation

of the Earth

U.S. Naval Observatory

ashington, D.C. U.S.A. 20390

Telephone: (202) 254-4023
Solar-Terrestrial Physics
(Solar and Interplanetary
Phenomena, lonospheric
Phenomena, Flare-Associated
Events, Geornagnetic Vari-
ations, Magnetospheric and
Interplanetary Magnetic
Phenomena, Aurora, Cosmic
Rays, Airglow):
World Data Center A
for Solar-Terrestrial Physics
Environmental Data and
Information Service, NOAA
Boulder, Colorado, U.S.A. 80303
Telephone: (303) 499-1000,
Ext. 6467
Solid-Earth Geophysics
(Seismology, Tsunamis, Gravi-
metry, Earth Tides, Recent
Movements of the Earth's
Crust, Magnetic Measure-
ments, Paleomagnetism
and Archeomagnetism, Volca-
nology, Geothermics):
World Data Center A
for Solid-Earth Geophysics
Environmental Data and
Information Service, NOAA
Boulder, Colorado, U.S.A. 80303
Telephone: (303) 499-1000,
Ext. 6521

ABOUT THE AUTHOR: Currently the Director of World Data Center A for Solid-Earth Geophysics and Deputy Director of the National Geophysical and Solar-Terrestrial Data Center in Boulder, Colorado, U.S.A., James F. Lander has been concerned with international geophysical data during most of his professional career. Prior to assuming his present responsibilities, he served as Director of the National Earthquake Information Center in Washington and in Boulder, U.S.A.

PLATE TECTONICS of the northern hemisphere in a precisely scaled, $25: 1$ exaggeration of the land masses and sea floors. Model description and prices on request. Slides \$5., 25 for $\$ 100$. $8 \times 10$ stereo pairs \$20.

Lith@sphere

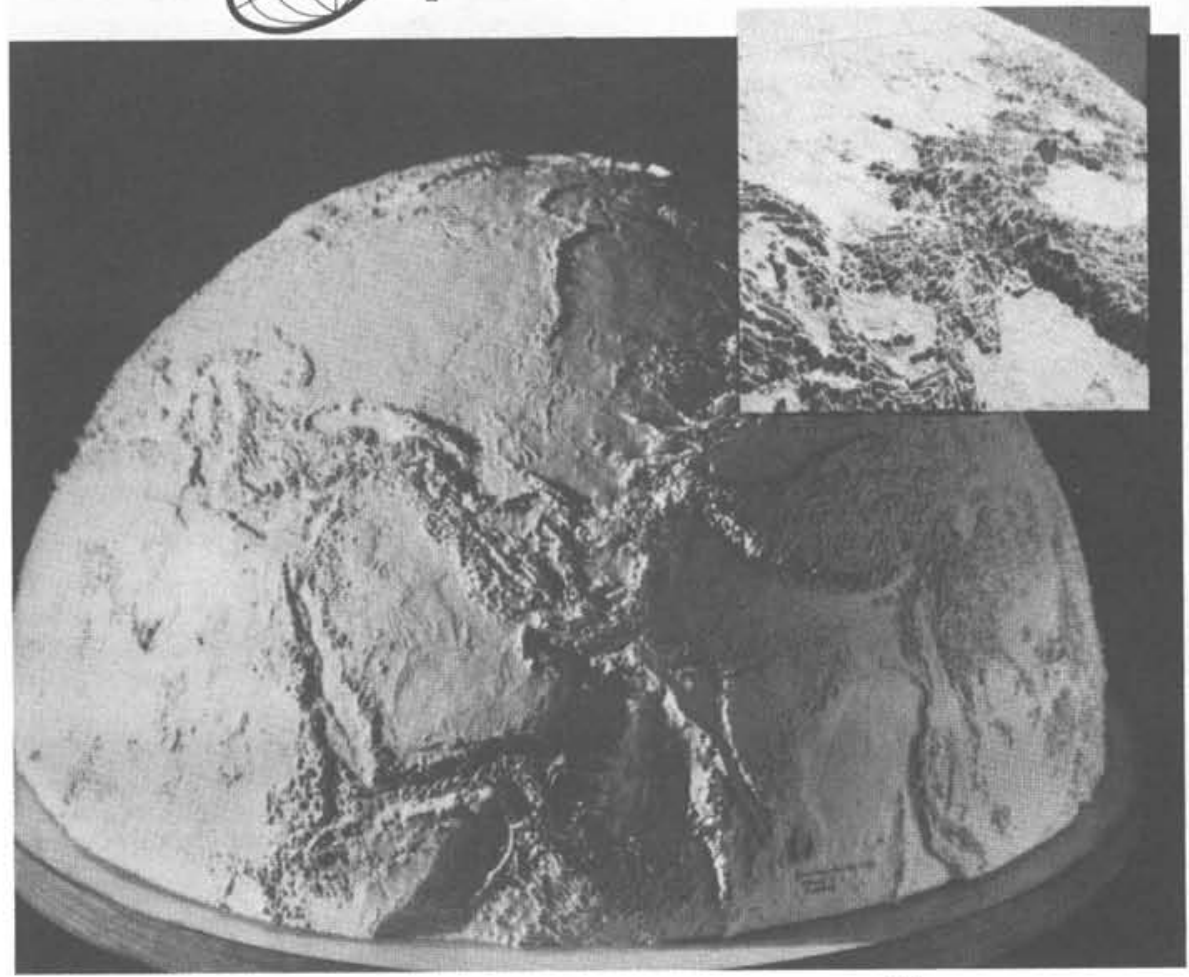

Partial list of reference sources:

T.E. Chase, et al, (Scripps), Bathymetry of the North Pacific

U.S.A.F. IN Series Jet Navigation Charts

U.S.S.R. World Atlas, 1967

U.N.E.S.C.O. General Bathymetric Chart of the Oceans, 1975

London Times Atlas

U.S. Department of Commerce, Office of Technical Services (Goncharov and Mikhaylov), New Data on the Bottom Relief of the Mediterranean Sea

B.C. Heezen and M. Tharp,

Physiographic Diagram of the North Atlantic; Physiographic Diagram of the South Atlantic

U.S. Geological Survey

Woods Hole Oceanographic Institute

The LITHOSPHERE also shows topography and geomorphology from hundreds of research publications. 